ELECTRONIC LETTER

\title{
Refinement of the deletion in 7q21.3 associated with split hand/foot malformation type 1 and Mondini dysplasia
}

\author{
I Wieland, P Muschke, S Jakubiczka, M Volleth, B Freigang, P F Wieacker
}

J Med Genet 2004;41:e54 (http://www.jmedgenet.com/cgi/content/full/41/5/e54). doi: 10.1136/jmg.2003.010587

S plit hand/foot malformation type I (SHFMl, OMIM *183600) is an autosomal dominant developmental disorder of limb formation that results in the absence of the central digital rays, deep median clefts, and syndactyly of the remaining digits. Patients with SHFMl harbour deletions, translocations, and inversions in chromosomal region $7 \mathrm{q} 21-\mathrm{q} 22 .{ }^{1}$ The deletions at 7q21-q22 encompass different genomic regions and probably result in a contiguous gene syndrome that includes growth impairment, microcephaly, craniofacial manifestations, hernias, hearing loss, and mental retardation..$^{2}$ Cases with translocations do not show this broad pattern of abnormalities but are associated with hearing loss in most cases. ${ }^{45}$ Split hand/foot malformation type I is the only form of split hand/foot malformation associated with sensorineural hearing loss, and it has been designated SHFMID (OMIM *605617). ${ }^{56}$ Recently, SHFMID was shown to result from Mondini dysplasia in a boy with a de novo deletion of about 8.9$17 \mathrm{cM}$ of the paternal chromosome $7 \mathrm{q} 21.1-\mathrm{q} 21.3 .^{7}$ So far, microdeletions at $7 \mathrm{q} 21.3$ have been described in only two cases: one in a boy with split hand/foot malformation plus mild mental retardation, growth retardation of post-natal onset, and hypotonia and another in a patient with ectrodactyly, ectodermal dysplasia, and cleft lip/palate (EEC) syndrome. ${ }^{89}$ Mapping of the deletion and translocation breakpoints in several patients showed a critical interval of about $1 \mathrm{Mb}$ for the SHFMl locus at 7q21.3. ${ }^{9}$ This interval included a $500 \mathrm{~kb}$ region that spanned five of seven known translocation breakpoints. In this region, the candidate genes $D L X 5$ and DLX6 (human homologues of the Drosophila distalless homeobox gene family) and DSSI (deleted in the split hand/split foot SHFMl region) were identified. No mutations were detected in patients with sporadic split hand/foot malformation with translocations or two families with split hand/foot malformation, sensorineural deafness, and normal chromosomes who showed linkage to $7 \mathrm{q} 21 .^{69^{10}}$ Haploinsufficiency through interruption of the gene's regulatory elements was considered therefore to be the cause of SHFMl. Recently, an animal model of human SHFMl has been produced in mice by targeted inactivation of Dlx5 and Dlx6 candidate genes. ${ }^{11}{ }^{12}$ In this mouse model, the Dl $\times 5 /$ Dl $x 6^{-1-}$ genotype resulted in inner ear and severe limb malformations and craniofacial and axial skeletal defects. ${ }^{11}$

\section{CLINICAL SUMMARY}

The index patient was the four year old son of a 28 year old mother and a 32 year old father who were healthy and not consanguineous. The child was born in the 42nd week of pregnancy. His weight at birth was $3630 \mathrm{~g}$, length at birth $50 \mathrm{~cm}$, and fronto-occipital circumference $36.0 \mathrm{~cm}$. The patient was referred to our department at the age of four weeks because of split hand/split foot malformation. He had ectrodactyly of the left hand and both feet, with typical lobster claw (fig 1). The right hand had syndactyly of the third and fourth digits. Further dysmorphic features were

\section{Key points}

- Split hand/foot malformation type I (SHFMI, OMIM *183600) is characterised by missing digits, syndactyly, and deep median clefts in the hands and feet, and it may be associated with sensorineural hearing loss (SHFM1D, OMIM *605617). The disease locus has been located to chromosome 7q21.3-q22 by the use of deletion mapping and linkage analysis.

- We report a boy with a de novo microdeletion of $0.9-1.8 \mathrm{Mb}$ in the SHFM1 region, with classical symptoms of SHFMI and deafness caused by Mondini dysplasia. Haplotype analysis with microsatellite markers showed loss of the paternal alleles D7821, D7S491, and D7624. The microdeletion included the candidate genes DSS1, DLX5, and DLX6, whereas two copies of the flanking DNCI1 gene were retained in the patient's genome. In all three cases of SHFM1 investigated by haplotype analysis, the paternal alleles were missing.

dysplastic ears and retrognathia. A hearing test showed profound deafness. Examination by magnetic resonance tomography showed a malformation of the inner ear typical for Mondini dysplasia, including enlargement of the vestibulum and a plump cochlea structure. Cochlea implantation was performed at the left side. To date, psychomotoric development seems normal.

\section{MATERIALS AND METHODS \\ Microsatellite analysis}

Fourteen microsatellite markers from chromosome 7q21.3q22.1 retrieved from the NCBI STS map (www.ncbi. nlm.nih.gov/) were informative in the family. Primers for polymerase chain reaction (PCR) were synthesised commercially (MWG-Biotech, Ebersberg, Germany), and standard PCR analysis was performed. ${ }^{13}$

\section{Southern blot hybridisation}

We cleaved high molecular weight DNA with restriction endonuclease Hind III. We resolved the digests on $0.8 \%$ agarose gel and blotted them on a nylon membrane (Hybond-N+, Amersham Biosciences, Little Chalfont, UK). We produced hybridisation probes DNCIl (accession number NM_004411), DLX5 (accession number NM_005221), and DXLE (accession number NM_005222) by amplification of cDNA templates from placenta and fetal brain tissue (Clontech, Palo Alto, CA, USA) with PCR primers DNCIIfor 5'AGAAGAGAAGAAACGGAAGG3' and DNCIlrev 5'CAGG AACACATTTTGCCATC3' to give a 1188 bp PCR product, DLX5for 5'CGTCTCAGGAATCGCCAACT3' and DLX5rev 
5'ACTGGTTGGAGGTCGGAGG3' to give a 651 bp PCR product, and DLX6for 5'ACTCGCAGCACAGCCCTTAC3' and DLX6rev 5'CTGCATCGTGTCCTGGTGT3' to give a $513 \mathrm{bp}$ PCR product. Annealing temperatures were $55^{\circ} \mathrm{C}$ for DNCIl and $61^{\circ} \mathrm{C}$ for DLX5 and DLX6. We performed PCR amplifications with the Enhanced High Fidelity PCR System (Roche Diagnostics, Basel, Switzerland). We purified PCR products with a QIAEX II Gel Extraction Kit (Qiagen, Hilden, Germany) and radiolabelled them by random priming with alpha- ${ }^{32} \mathrm{P}$ dCTP. We carried out hybridisations, washings, and autoradiography according to standard protocols. ${ }^{14}$

\section{RESULTS}

Chromosome analysis from the phytohemagglutinin stimulated lymphocytes of the patient showed a normal karyotype, apart from a heteromorphism in chromosome 9 (karyotype: $46, \mathrm{XY}, 9 \mathrm{qh}-)$. This heteromorphism was also detected in the mother $(46, \mathrm{XX}, 9 \mathrm{qh}-)$. The karyotype of the father was inconspicuous $(46, \mathrm{XY})$. In the patient, no deletion in chromosome 7 could be detected at a banding level of 400 , and no abnormal comparative genomic hybridisation pattern was seen (data not shown), which suggests the possibility of a split-hand/foot malformation microdeletion in this patient. Haplotype analysis of the SHFMl critical region at 7q21.3q22.1 of the parents and their affected son showed unambiguous loss of the paternal markers D7S821, D7S491, and D7S624, whereas the flanking markers D7S2482 and D7S618 retained heterozygosity (table 1, fig 2). Additional markers within this interval were found to be uninformative. To delineate the deletion further, we performed quantitative Southern blot analysis of the genes DLX5, DLX6, and DNCI1 (dynein cytoplasmic intermediate polypeptide 1) within the interval. For the DNCIl gene, signal intensity was the same in the affected boy, his parents, and a normal control person (fig 3). In contrast, for the $D L X 5$ and $D L X 6$ genes, signal intensities in the affected boy were reduced clearly to about half those of his parents and the control person (fig 3). These data suggest retention of both parental copies of the DNCII gene but loss of one copy of each of the DLX5 and DLX6 genes in the affected boy. From these results, the deletion breakpoints are located between the DNCII gene and marker D7S82 1 at the proximal border and between the DLX5 gene and marker D7S618 at the distal border. This narrows the deletion to $0.9-1.8 \mathrm{Mb}$ (table 1).

\section{DISCUSSION}

We report the first patient with a microdeletion in $7 q 21.3$ who shows SHFMl with Mondini dysplasia. This microdeletion includes the SHFMl candidate genes $D L X 5, D L X 6$, and DSS1. In mice, all three candidate genes apparently are

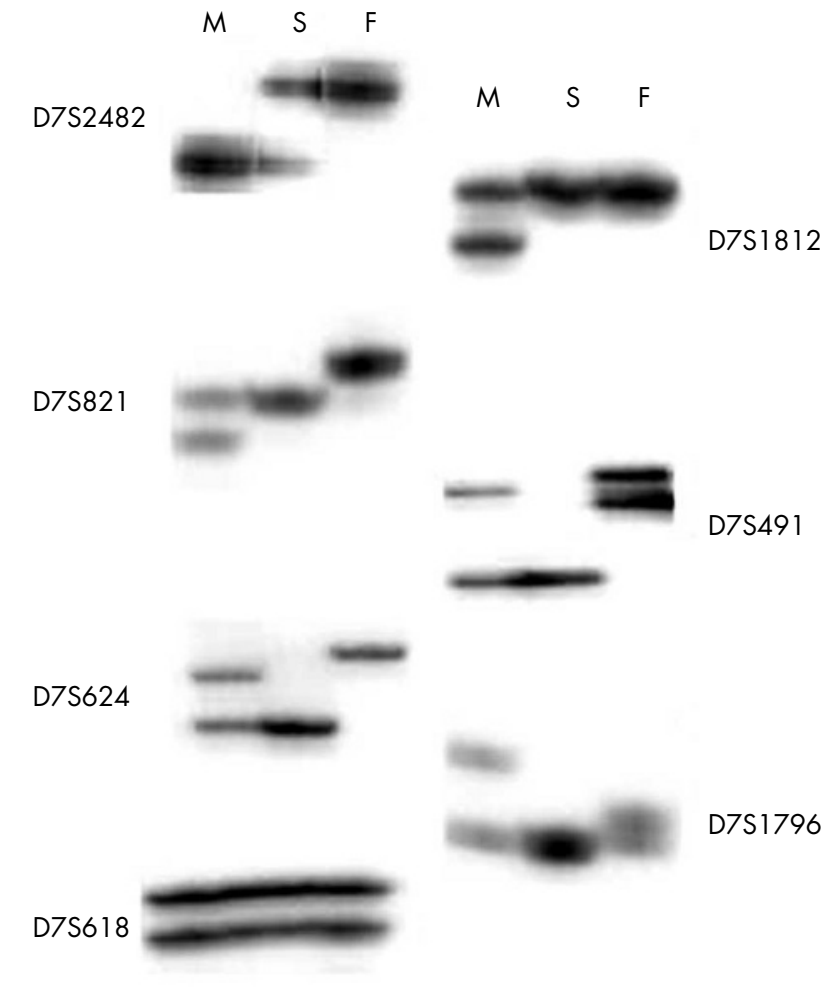

Figure 2 Analysis of microsatellite markers from the critical SHFM1 region. Marker positions are listed in table 1. Genotypes of the mother $(M)$, son (S), and father (F) for the indicated markers are shown.

involved in limb formation. ${ }^{9}{ }^{11} 12$ The Dlx5 and Dlx6 genes mostly are coexpressed in a unique spatial and temporal pattern. Knockout mice that solely lack the $D l \times 5$ gene show no apparent limb abnormalities. ${ }^{15}$ Furthermore, the SHFM phenotype was apparent only in $D l \times 5 / 6^{-1-}$ double knockout mice and could be rescued by transgenic overexpression of the Dlx5 gene. ${ }^{11}$ This suggests that the Dlx5 and Dlx6 genes functionally are redundant in controlling limb and craniofacial development in mice. ${ }^{11}{ }^{16}{ }^{17}$ Interestingly, Dl $x 5 / D l \times \sigma^{-}$ mice have disturbed development of the inner ear. From the mouse model, it seems possible that deletion of DLX5 and $D L X 6$ also causes Mondini dysplasia in SHFMID. The role of the DSS1 gene in limb formation is less clear. In yeast, deletion of the DSSI homologue SEMI induces pseudohypheal growth under differentiating conditions. ${ }^{18}$ SEMI and DSSI
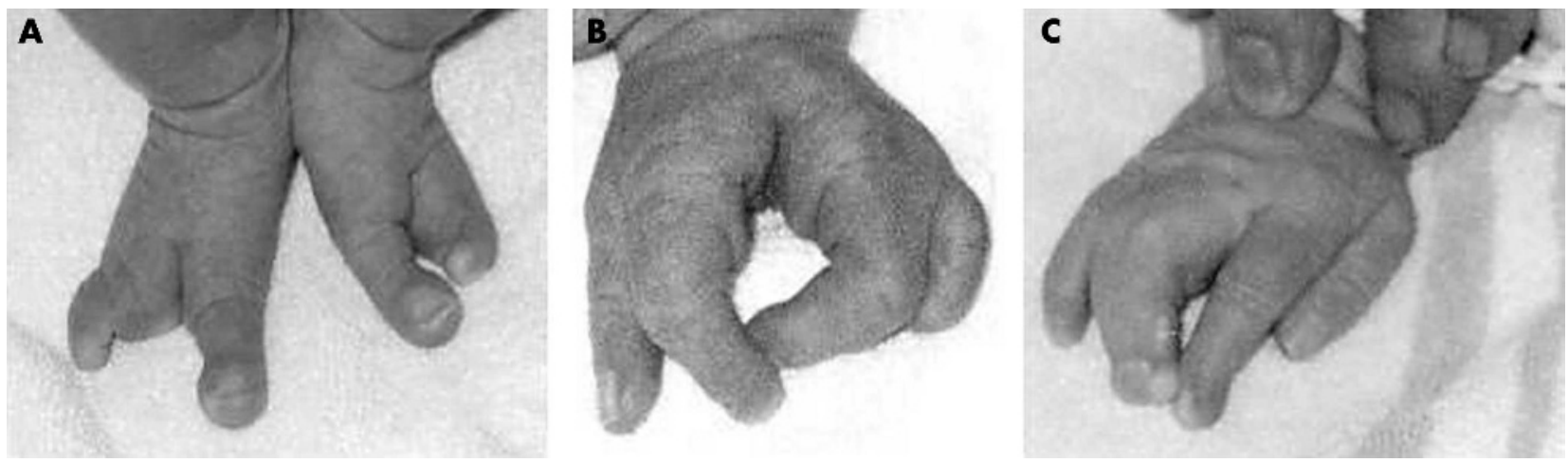

Figure 1 Ectrodactyly of both feet (A) and the left hand (B), with lobster claw malformation. The right hand (C) had syndactyly of the third and fourth fingers. 

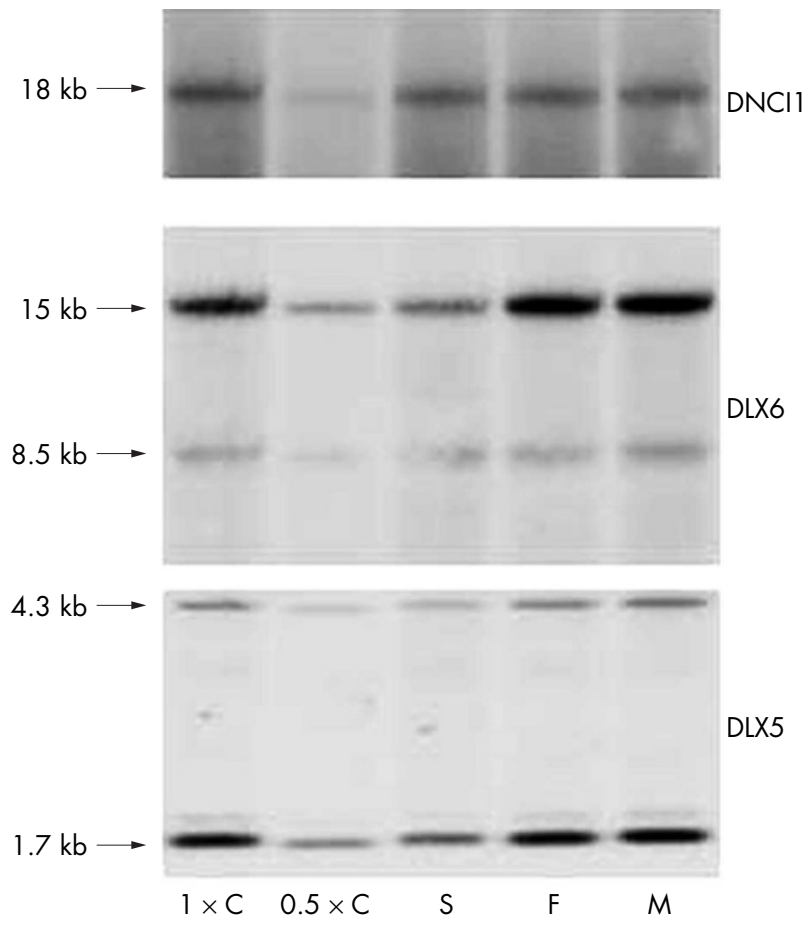

Figure 3 Southern blot analysis of the DNCI1, DLX6, and DLX5 genes with corresponding CDNA probes. Equal amounts of DNA from the son $(S)$, father $(F)$, mother $(M)$, and a control person $(1 \times C)$ and half the amount $(0.5 \times C)$ of the control DNA, respectively, were separated by agarose gel electrophoresis. Hind III cleaved phage $\lambda$ DNA was used to calculate the fragment sizes shown on the left.

functionally are conserved, as DSSI was able to restore the pseudohypheal phenotype in yeast. SEMI is a vesicle transport protein and seems to act as a negative regulator for exocyst function. The role of membrane traffic in mammalian development, however, is poorly understood.

Table 1 Genotype analysis in the SHFM1 interval on 7q21.3-q22.1

\begin{tabular}{|c|c|c|c|c|}
\hline \multirow[b]{2}{*}{ Marker* } & \multirow{2}{*}{$\begin{array}{l}\text { Marker's position on } \\
\text { chromosome } 7 \text { (kbp) }\end{array}$} & \multicolumn{3}{|c|}{ Genotype } \\
\hline & & Mother & Son & Father \\
\hline D7S2410 & 88915 & $1-2$ & $1-3$ & $3-3$ \\
\hline D7S657 & 91342 & $1-2$ & $1-2$ & $1-2$ \\
\hline D7S3050 & 92238 & $1-2$ & $1-2$ & $1-1$ \\
\hline D7S2482 & 93658 & $2-2$ & $1-2$ & $1-1$ \\
\hline D7S527 & 94151 & $1-2$ & $2-2$ & $2-2$ \\
\hline DNCl1† & $\sim 94000$ & ++ & ++ & ++ \\
\hline D7S1812 & 94293 & $1-2$ & $1-?$ & $1-1$ \\
\hline D7S821 & 94593 & $2-3$ & 2-del & $1-1$ \\
\hline D7S491 & 95031 & $2-4$ & 4-del & $1-3$ \\
\hline D7S624 & 95062 & $2-3$ & 3-del & $1-1$ \\
\hline D7S1796 & 95088 & $1-3$ & 3-?del & $2-3$ \\
\hline AFM284ZC1 & 95089 & $1-2$ & 2-?del & $1-2$ \\
\hline DLX6† & $\sim 95200$ & ++ & + & ++ \\
\hline DLX5† & $\sim 95200$ & ++ & + & ++ \\
\hline D7S618 & 95854 & $1-2$ & $1-2$ & $1-2$ \\
\hline D7S554 & 95860 & $3-3$ & $2-3$ & $1-2$ \\
\hline D7S651 & 97083 & $1-2$ & $2-3$ & $2-3$ \\
\hline
\end{tabular}

del, deletion of the paternal allele.

*Microsatellite markers used for haplotype analysis and their corresponding position on chromosome 7 in kbp are from NCBI maps (www.ncbi.nml.nih.gov/).

† Approximate position of genes in kbp (www.ncbi.nml.nih.gov/) and copy number for genes (,++ 2 copies;,+ 1 copy); the DSS1 gene is located between markers D7S821 and D7S491.
In contrast to the situation in mice, contiguous loss of one allele of the SHFMl candidate genes seems to be enough to cause the SHFMl phenotype in humans. Most deletions in SHFMl were detected cytogenetically, and only in two previously reported cases was haplotype analysis performed. ${ }^{37}$ Surprisingly, in these two cases, as well as in the case presented here, the de novo deletions occurred on the paternal chromosome 7 . This may indicate preferential loss of the paternal alleles in SHFMl. Recently, a new imprinted gene cluster on human chromosome 7q21, which includes the $\epsilon$-sarcoglycan gene and the paternally expressed 10 (PEG 10) gene, has been suggested. ${ }^{19} 20$ Both genes are located about $2 \mathrm{Mb}$ proximal of the SHFMl critical region and seem to be imprinted maternally. Linkage analysis in one of two SHFMID families, however, does not support a role of maternal imprinting in SHFMI because maternal transmission of the disease was observed for six of nine female family members. ${ }^{6}$ Haplotype analysis of a larger number of patients with SHFMl with de novo deletions on chromosome 7 could show whether the paternal chromosome 7 is prone to deletion of the SHFMl region.

\section{ACKNOWLEDGEMENTS}

We thank Dr G Klingebiel, Berlin, for his expertise on magnetic resonance topography scanning, and G Koch and G Weilepp for technical assistance.

\section{Authors' affiliations}

I Wieland, P Muschke, S Jakubiczka, M Volleth, P F Wieacker, Institut für Humangenetik, Universitätsklinikum, Otto-von-Guericke-Universität, Leipziger Str. 44, 39120 Magdeburg, Germany

B Freigang, Universitätsklinik für HNO-Heilkunde, Otto-von-GuerickeUniversität, Leipziger Str. 44, 39120 Magdeburg, Germany

Conflicts of interest: none declared.

Correspondence to: Professor P Wieacker, Institut für Humangenetik, Universitätsklinikum, Otto-von-Guericke-Universität, Leipziger Str. 44, 39120 Magdeburg, Germany; peter.wieacker@medizin.unimagdeburg.de

Received 19 May 2003

Accepted for publication 19 June 2003

\section{REFERENCES}

1 Duijf PHG, van Bokhoven H, Brunner HG. Pathogenesis of split-hand/split-foot malformation. Hum Mol Genet 2003;12:R51-60.

2 Morey MA, Higgins RR. Ectro-amelia syndrome associated with an interstitial deletion on 7q. Am J Med Genet 1990;35:95-9.

3 Marinoni JC, Stevenson RE, Evans JP, Geshuri D, Phelan MC, Schwartz CE. Split foot and developmental retardation associated with a deletion of three microsatellite markers in 7q21.2-q22.1. Clin Genet 1995;47:90-5.

4 Ignatius J, Knuutila S, Scherer SW, Trask B, Kere J. Split hand/split foot malformation, deafness, and mental retardation with a complex cytogenetic rearrangement involving 7q21.3. J Med Genet 1996:33:507-10.

5 Genuardi M, Pomponi MG, Sammito V Bellussi A, Zollino M, Neri G. Split/ hand split foot anomaly in a family segregating a balanced translocation with a break point on 7q22.1. Am J Med Genet 1993;47:823-31.

6 Tackels-Horne D, Toburen A, Sangiorgi E, Gurrieri F, de Mollerat X Fischetto R, Causio F, Clarkson K, Stevenson RE, Schwartz CE. Split hand/split foot malformation with hearing loss: first report of families linked to SHFM1 locus in 7q21. Clin Genet 2001;59:28-36.

7 Haberlandt E, Löffler J, Hirst-Stadlmann A, Stöckel B, Judmaier W, Fischer H, Heinz-Erian P, Müller T, Utermann G, Smith RJH, Janecke AR. Split hand/split foot malformation associated with sensorineural deafness, inner and middle ear malformation, hypodontia, congential vertical talus, and deletion of eight microsatellite markers in 7q21.1-q21.3. J Med Genet 2001;38:405-9.

8 Hudgins L, Massa H, Disteche C, Scherer SW, Tsui L-C, Trask B, Evans JP. Identification of a microdeletion at 7q21.3 with fluorescence in situ hybridization with split hand/split foot (ectrodyctyly). Am J Hum Genet 1994;3:A107.

9 Crackower MA, Scherer SW, Rommens JM, Hui CC, Poorkaj P, Soder S, Cobben JM, Hudgins L, Evans JP, Tsui LC. Characterization of the split hand/ split foot malformation locus SHFM1 at 7q21.3-q22.1 and analysis of a candidate gene for its expression during limb development. Hum Mol Genet 1996;5:571-9

10 Scherer SW, Poorkaj P, Allen T, Kim J, Geshuri D, Nunez M, Soder S, Pagon R, Stephens K, Patton M, Rivera H, Berg MA, Pfeiffer RA, Naritomi K, 
Hughes $\mathrm{H}$ Genuardi M Gurrieri F, Neri G, Lovrein E, Magenis E Tsui L-C, Evans JP. Fine mapping of the autosomal dominant split hand/split foot locus on chromosome 7, band q21.3-q22.1. Am J Hum Genet 1994;55:12-20.

11 Robledo RF, Rajan L, Li X, Lufkin T. The D/x5 and Dlx6 homeobox genes are essential for craniofacial, axial, and appendicular skelefal development. Genes Dev 2002;16:1089-101.

12 Merlo GR, Paleari L, Mantero S, Genova F, Beverdam A, Palmisano GL, Barbieri O, Levi G. Mouse model of split hand/foot malformation type I. Genesis 2002;2:97-101.

13 Wieland I, Muschke P, Wieacker P. Further delineation of Wittwer syndrome and refinement of the mapping region. Am J Med Genet 2003;1 16:57-60.

14 Sambrook J, Fritsch EF, Maniatis T. Molecular cloning: a laboratory manual. Cold Spring Harbor: Cold Spring Harbor Laboratory Press, 1989.

15 Acampora D, Merlo GR, Paleari L, Zerega B, Postiglione MP, Mantero S, Bober E, Barbieri O, Simeone A, Levi G. Craniofacial, vestibular and bone defects in mice lacking the Distal-less-related gene Dlx5. Development 1999; 126:3795-809.
16 Depew MJ, Liu JK, Long JE, Presley JE, Meneses JJ, Pedersen RA Rubenstein JL. Dlx5 regulates regional development of the branchial arches and sensory capsules. Development 1999;126:3831-46.

17 Charite J, Mc Fadden DG, Merlo G, Levi G, Clouthier DE, Yanagisawa M Richardson JA, Olson EN. Role of Dlx6 in regulation of an endothelin-1dependent, dHAND branchial arch enhancer. Genes Dev 2001;15:3039-49.

18 Jäntti J, Lahdenranta J, Olkkonen VM, Söderlund H, Keränen S. SEMI, a homologue of the split hand/split foot malformation candidate gene Dss 1 , regulates exocytosis and pseudohyphal differentiation in yeast. Proc Natl Acad Sci USA 1999;96:909-14.

19 Zimprich A, Grabowski M, Asmus F, Naumann M, Berg D, Bertram M, Scheidłmann K, Kern P, Winkelmann J, Müller-Myhsok B, Riedel L, Bauer M, Müller T, Castro M, Meitinger T, Strom TM, Gasser T. Mutations in the gene encoding $\epsilon$-sarcoglycan cause myoclonus-dystonia syndrome. Nature Genet 2001;29:66-9

20 Ono R, Kobayashi S, Wagatsuma H, Aisaka K, Kohda T, Kaneko-Ishino T, Ishino F. A retrotransposon-derived gene, PEG 10, is a novel imprinted gene located on human chromosome 7q21. Genomics 2001;73:232-7. 